\title{
Influence of climate change impacts and mitigation costs on inequality between countries
}

\author{
Nicolas Taconet - Aurélie Méjean • \\ Céline Guivarch
}

\begin{abstract}
This is the accepted version of the following article: Taconet, N., Mejean, A. \& Guivarch, C. Influence of climate change impacts and mitigation costs on inequality between countries. Climatic Change 160, 1534 (2020). DOI: 10.1007/s10584-019-02637-w
\end{abstract}

9 Abstract Climate change affects inequalities between countries in two ways. On the one hand, rising temperatures from greenhouse gas accumulation cause impacts that fall more heavily on low-income countries. On the other hand, the costs of mitigating climate change through reduced emissions could slow down the economic catch-up of poor countries. Whether, and how much the recent decline in between-country inequalities will continue in the twenty-first century is uncertain, and the existing projections rarely account for climate factors. In this study, we build scenarios that account for the joint effects of mitigation costs and climate damages on inequality. We compute the evolution of country-by-country GDP, considering uncertainty in socioeconomic assumptions, emission pathways, mitigation costs, temperature response, and climate damages. We analyze the resulting 3408 scenarios using exploratory analysis tools. We show that the uncertainties associated with socioeconomic assumptions and damage estimates are the main drivers of future inequalities. We investigate under which conditions the cascading effects of these uncertainties can counterbalance the projected convergence of countries' incomes. We also compare inequality levels across emission pathways, and analyze when the effect of climate damages on inequality outweigh that of mitigation costs. We stress the divide between IAM- and econometrics-based damage functions in terms of their effect on inequality. If climate damages are as regressive as the latter suggest, climate mitigation policies are key to limit the rise of future inequalities between countries.

N. Taconet and C. Guivarch

ENPC, CIRED - Centre International de Recherche sur l'Environnement et le Développement. E-mail: taconet@centre-cired.fr

A. Méjean

CNRS, CIRED - Centre International de Recherche sur l'Environnement et le Développement 
31 Keywords Climate change - Inequality - Gini - Scenario analysis - Climate

32 mitigation $\cdot$ Socioeconomic scenario . Climate change impact 


\section{Introduction}

Income inequalities between countries have declined in recent decades notably as a result of rapid economic growth in China and India (Firebaugh, 2015. Milanovic, 2016). Most projections see inequalities continuing along this dwindling path throughout the twenty-first century (Hellebrandt and Mauro, 2015 Riahi et al., 2017, OECD, 2018, Rodrik, 2011, Hawksworth and Tiwari, 2011. Spence, 2011). However, they do not consider the impact of climate change on inequalities. Indeed, climate change will induce impacts that hit primarily the poorest countries (Oppenheimer et al., 2014; Burke et al., 2015; Nordhaus 2014, Mendelsohn et al., 2006, Stern, 2007; Tol, 2018), which may slow or even reverse the expected convergence of per capita national incomes. Limiting these impacts through greenhouse gas reduction policies also bears consequences for inequalities, as mitigation policies could be a hurdle to development. How the distributional effects of reduced climate change damages compare with those of mitigation costs and how they weigh against other socioeconomic factors have not been analyzed. Our paper bridges this gap.

We analyze how climate change affects future inequalities between countries via joint impacts and mitigation costs. We build country-by-country GDP trajectories up to 2100, exploring the uncertainty around 6 dimensions: (1) socioeconomic assumptions, (2) emission pathways, (3) mitigation costs, (4) regressivity of mitigation costs, (5) temperature response, (6) climate change damages. The different combinations of uncertainties lead us to explore 3408 scenarios, for which we analyze between-country inequality as measured by the Gini coefficient, as well as the first income decile. We perform a statistical analysis of the outcomes to identify the main drivers of future inequality. We find that the burden of climate damages on poor countries is sufficiently large to lead to a reversal in the declining inequality trend in some combinations of socioeconomic pathways and damage estimates. We also analyze inequality levels of various emission pathways, showing that lower emissions are associated with a lower level of inequalities under the strongest damage estimates. If damage estimates are low, mitigation can still reduce inequalities in some combinations of assumptions regarding socioeconomic evolution, the level of mitigation cost and the distribution of these costs.

We discuss the drivers of future inequality in Section 2, We then present the methodology used to build scenarios in Section 3 . We analyze the results of the projections in Section 4. We discuss limitations and conclude in Section 5.

\section{Drivers of future inequality}

We consider two types of factors affecting future economic growth: climaterelated and socioeconomic factors. Climate change affects between-country inequality in two ways: through uneven climate damages and through differentiated mitigation costs. 
First, climate change is expected to reduce future income, through direct production and capital losses and lower economic growth. It is also expected to increase investment needs for adaptation. These climate damages will be shared unevenly among countries, because physical impacts may differ, and because the vulnerability to climate change and the ability to adapt vary widely across countries. For instance, some countries are more dependent than others on sectors that will be affected by climate change, such as the agricultural sector. Damage evaluation is a perilous exercise: it is very difficult, if not impossible, to predict how each country will be impacted by climate change. However, an extensive literature suggests that overall damages of climate change will be greater in poorer countries (Oppenheimer et al., 2014, Tol et al., 2004: Mendelsohn et al. 2006: Burke et al. 2015: Nordhaus and Yang, 1996: Hallegatte and Rozenberg, 2017, Dell et al. 2012), and the Intergovernmental Panel on Climate Change lists the distribution of impacts as one of the five "Reasons for Concern" about climate change.

Second, the cost of greenhouse gas emission reductions will affect countries' future income, with the costs depending on local contexts. For instance, current carbon intensities differ widely across countries, as do their potentials for the development of renewable energy. Mitigation policies can be more burdensome for low-income countries than for rich countries, meaning that poor regions may lose a greater share of GDP than rich regions for the same amount of abated emissions (Krey, 2014, Edenhofer et al., 2014). Indeed, low-income economies are often characterized by higher energy and carbon intensities. By raising the price of energy, mitigation policies could thus hamper their ability to develop. Higher costs in low-income countries can also arise due to term of trade effects of climate policy (Leimbach et al., 2010). Some mitigation strategies, notably using biofuels, could also threaten food security in the poorest regions (Hasegawa et al., 2018, Fujimori et al., 2019). However, the actual regressivity of mitigation costs will depend on the way the burden of the emission reduction effort is shared among countries in the post-COP21 agenda (Aldy et al., 2017; Liu et al., 2016) and on the feasibility of international transfers (Fujimori et al., 2016).

Climate damages and the economic impacts of mitigation policies are closely intertwined, as the greater the emission reductions through mitigation policies, the smaller the damages. Thus, while greenhouse gas emission reduction may place a greater burden on poor countries, it also reduces future damages that fall disproportionately on them, so that the resulting effect of mitigation is ambiguous in terms of inequality: avoided climate change may reduce inequality only if mitigation costs do not fall too heavily on the poorest countries. Yet, no study has brought both sides of the issue together to study future inequalities. Here, we analyze inequalities between countries for different emission pathways.

Climate-related factors are only one piece of the future inequality puzzle, as other socioeconomic factors affect the gap between rich and poor countries, such as demographics, technological progress, education, and institutions (Barro and Sala-i Martin, 2004). A key question concerns the ability of 
Table 1 The Shared Socioeconomic Pathways (SSP)

\begin{tabular}{l|l}
\hline SSP & Name \\
\hline \hline 1 & Sustainability \\
2 & Middle of the Road \\
3 & Regional Rivalry \\
4 & Inequality \\
5 & Fossil-fueled Development \\
\hline
\end{tabular}

low income countries to mimic China and India's rapid economic catch-up. Whether convergence is just a question of time, occurs only regionally or is country-specific is the subject of intense debates in the development literature (Milanovic, 2006, Rodrik, 2011), and how fast the income of different countries can converge in the twenty-first century remains deeply uncertain.

\section{Methodology}

\subsection{Building the scenarios}

We build scenarios to explore future inequalities between countries, accounting for socioeconomic and climate-related factors. We model 6 dimensions of uncertainties: (1) socioeconomic assumptions, (2) emission pathways, (3) mitigation cost estimates, (4) regressivity of mitigation costs, (5) temperature response, (6) climate change damages. A summary of the uncertainties and sources considered is provided in table 2 .

\subsubsection{Socioeconomic assumptions}

We use shared socioeconomic pathways (SSP) scenarios to explore possible evolutions of socioeconomic factors in the twenty-first century (Riahi et al. 2017). SSPs consist of five pathways (SSPs 1 to 5) that reflect combined and consistent hypotheses on demographics, technological progress, and socioeconomic evolutions (see table 1). SSPs project economic growth for all countries based on future population, technological progress, physical and human capital, as well as energy and fossil resources (Dellink et al., 2017). While SSPs 1 and 5 depict sustained growth and convergence of income levels by the end of the century, in SSPs 3 and 4 poor prospects for developing countries and lack of cooperation lead to much slower reduction of inequality. SSP 2 lies in between, with moderate growth and convergence. For each country, initial GDP per capita levels in 2015 are set using the latest World Development Indicators (WDI 2017, May), and economic growth is set based on SSP trajectories ${ }^{1}$

1 SSP trajectories are available at SSP Database (Version 2.0). 


\subsubsection{Emission pathways}

The SSP growth projections for all countries assume there are no climate policy and no climate change impacts. We build on these projections to compute projections for different mitigation pathways with radiative forcing targets corresponding to representative concentration pathways (RCPs). The radiative forcing levels reached in the baseline case in 2100 differ across SSPs, with the highest - SSP 5 - being the only one above RCP 8.5, while the lowest SSP 1 - is below RCP 6.0 (Riahi et al. 2017). Thus, we leave aside RCP 8.5 , and only keep RCPs 2.6, 4.5, and 6.0, to which we add the intermediary radiative forcing target of $3.4 \mathrm{~W} / \mathrm{m}^{2}$ from the SSP database. Of these, only RCP 2.6 is likely to meet the target of limiting global mean temperature increase below $2^{\circ} \mathrm{C}$ compared with pre-industrial levels (Stocker et al., 2013). For all mitigation scenarios, we account for mitigation costs to meet the target and for the economic impacts from a changing climate.

\subsubsection{Mitigation costs}

We compute mitigation costs based on regional projections from the SSP database, which provides the results from six different integrated assessment models (IAMs) for scenarios spanning the SSP-RCP matrix. We use mitigation costs calculated by the IAMs that include an endogenous growth module (AIM/GCE, MESSAGE-GLOBIUM, REMIND-M, and WITCH). Other IAMs in the SSP database (IMAGE and GCAM) assume exogenous GDP growth pathways that are not affected by mitigation policies and thus do not change according to the RCP. We exclude the results from these models, as they do not represent the effect of mitigation on growth. Of the four models, some have not run all SSPs, so we have between 2 and 4 estimates for each combination of SSP/RCP. A clear advantage of using the mitigation costs from the SSP database is that they are consistent with the storylines of the SSPs. Thus, the same target is more difficult to reach in a scenario where baseline emissions are large or technical progress is slow. However, the cost projections rely on a least-cost approach, which brings two caveats. First, the actual cost of reaching the target may in fact be higher due to real-world market imperfections, for instance if there is inertia or imperfect foresight (Waisman et al., 2012). Second, emission reductions are supposed to take place in the region where they are the cheapest, regardless of equity considerations. Given the limited cooperation and policy harmonization across countries on climate change issues at present, the distribution of costs may differ from those assumed in the SSP database. To account for different effort-sharing schemes, we use two variants of mitigation cost distribution: first, we distribute the regional costs from the IAMs within each region proportionally to each country's income. Second, we look at the more regressive case of equally-shared costs within a region. As we explain in section 5.1, more progressive distributions could be envisaged that would reflect different burden sharing approaches under international negoti- 
ations. Such distribution would strengthen the impact of climate damages on inequality relative to mitigation cost.

\subsubsection{Temperature response}

There is great variability in the evolution of temperature at the country level for a given RCP as given by climate models (Stocker et al., 2013). Therefore, we consider values for temperature changes corresponding to the mean, and the 10th and 90th percentile of outcomes. Temperature changes in 2100 are taken from the Climate Intercomparison Model Project CMIP52 CMIP5 provides national mean annual temperature changes in 2100 for RCPs 2.6, 4.5, 6.0 and 8.5. When the radiative forcing in 2100 of a scenario falls between two values provided by CIMP5, we perform a linear interpolation to calculate temperature change in 2100 . Using the 2100 value, we assume that temperatures increase linearly over time.

\subsubsection{Climate change damages}

Given that future climate change damages are very uncertain, we use 8 estimates from different sources for damages associated with different temperature changes, from Integrated Assessment Models, and from the econometrics literature.

Integrated assessment models are primarily used to analyze the interaction between climate and the economy (Nordhaus, 2008). In particular, they are used to derive optimal emissions pathways balancing the cost of mitigation with the benefits of avoided damages. However, they typically provide global damage estimates - and the damage estimates they rely on are global, too. RICE and FUND are notable exceptions: we therefore use estimates from RICE2010 (Nordhaus, 2014) ${ }^{3}$ We also draw upon estimates relying on the GTAP model (Global Trade Analysis Project). Roson and Sartori (2016) (RS hereafter) assess the economic changes associated with higher temperature in different sectors (agriculture, health, tourism...) for 140 regions. We use their aggregate estimates of the percentage change of GDP in a $3^{\circ} \mathrm{C}$ scenario compared with the associated baseline, for the different regions. This percentage GDP change may be positive or negative depending on the region. We assume that this effect on GDP grows proportionally with global temperature.

Finally, we use estimates from the econometrics literature, which shows evidence that temperature changes have impacted economic growth in the past, and more heavily so in poorer countries. This difference is attributed either to national development levels (Dell et al., 2012), or to mean temperature (Burke et al. 2015). Burke et al. (2015) (BHM hereafter) derive a damage function from historical GDP and temperature data. The authors econometrically estimate the effect of higher than average annual temperature, controlling for

\footnotetext{
2 https://climexp.knmi.nl/plot_atlas_form.py

3 We are not aware of publicly available regional damage estimates from FUND.
} 
other variables. They find a non-linear bell-shaped relationship between temperature and economic growth, showing a maximum for an annual average temperature of around $13^{\circ} \mathrm{C}$.

Additionally, we consider econometric estimates from Dell et al. (2012) (DJO hereafter), who find a strong and significant effect of temperature on growth in poor countries, while the effect for rich countries is small. We account for the future divide between rich and poor countries in two ways: (1) a static version, where poor countries are defined as those currently below median income, a definition that is set over the whole horizon, (2) a dynamic version, with current median income defining the threshold between poor and rich countries, thus allowing countries to switch status over time. This second version accounts for some form of adaptation where income growth compensates (here almost fully) the negative impact of climate change.

For both damage functions, we use the regressions with 0 and 5 -year lags. A distributed lag model with 5-lags adds up the effect of temperature in the current and 5 previous years. This allows capturing the cumulative effect of temperature on income rather than solely a short-run effect. We discuss the limitations of relying on econometric estimates to project future damages in section 5.1

\subsubsection{Computing economic growth}

Using mitigation costs and climate damages for each country, GDP per capita $Y$ at time $t$ in a given RCP scenario is calculated as follows, for RICE and RS:

$$
Y_{t, R C P}=X_{t, R C P} \Omega\left(G M T_{t}\right) Y_{t, \text { baseline }}
$$

where $X_{t, R C P}$ is the mitigation cost factor, $\Omega\left(G M T_{t}\right)$ is the damage factor in the region for a global mean temperature change of $G M T_{t}$, and $Y_{t, \text { baseline }}$ is the GDP per capita in the corresponding baseline scenario.

For econometrics-based damage functions (BHM and DJO), the equation writes:

$$
Y_{t, R C P}=X_{t, R C P}\left(1+g_{t, \text { baseline }}+\Delta g\left(T_{t}\right)\right) Y_{t-1, R C P}
$$

where $g_{t, b a s e l i n e}$ is the growth projected in a baseline without climate impacts and $\Delta g\left(T_{t}\right)$ is the loss of economic growth under national temperature $T_{t}$ due to climate change.

In total, we are able to compute the projections for 161 countries, currently representing $96 \%$ of world population. We exclude countries for which we lack either initial GDP or future temperature projections.

The combination of different socioeconomic assumptions (5 SSPs), emissions pathways (baseline and between 2 and 4 RCPs, depending on the SSP), mitigation costs estimates ( 2 to 4 estimates depending on the SSP and RCP, with 2 variants of the distribution of costs within region for each estimate), temperature response to a given RCP (3 cases), and damage estimates (8 
Table 2 Uncertain factors considered in the study

\begin{tabular}{l|l|l}
\hline Dimension & Levels & Source \\
\hline Socioeconomic & 5 growth pathways & SSP database \\
\hline Emissions & $\begin{array}{l}\text { baseline and lower pathways among } \\
\text { RCPs } 2.6,3.4,4.5,6.0\end{array}$ & SSP database \\
\hline Mitigation costs & regional costs from 2 to 4 models & SSP database \\
\hline $\begin{array}{l}\text { Distribution of } \\
\text { mitigation costs }\end{array}$ & $\begin{array}{l}\text { Equal distribution or proportional to } \\
\text { income within regions }\end{array}$ & \\
\hline Temperature & $\begin{array}{l}\text { Low (10th percentile), Medium } \\
\text { (mean), and High (90th percentile) }\end{array}$ & CMIP5 \\
\hline Damages & $\begin{array}{l}\text { damage functions (IAM- and } \\
\text { econometrics-based) }\end{array}$ & $\begin{array}{l}\text { RICE2010, Roson and } \\
\text { Sartori } \sqrt{(2016),}\end{array}$ \\
\cline { 2 - 3 } & et al. & $(2012)$, Burke \\
\hline
\end{tabular}

models) results in 3408 scenarios. Scenarios are consistent in the sense that for each combination, the mitigation costs are those estimated for the corresponding SSP/RCP, while climate damages are calculated according to the temperature change induced by the emission pathway against the temperature response. However, we ignore the fact that damages that damages for a given temperature change may also depend on the socioeconomic pathway. This limitation is discussed in section 5.1. Besides, some combinations of factors may be more plausible than others, but we nevertheless consider all of them without making a priori judgements about their likelihood.

\subsection{Measuring income inequality}

The literature distinguishes three types of income inequality (Milanovic, 2011): (1) unweighted international inequality compares countries' income regardless of their size, (2) population-weighted international inequality weighs countries' income according to their population (3) total inequality accounts for households' or individuals' revenue distributions within and across countries. We focus on the second type of inequality, which gives equal weight to all individuals across countries. This choice of international inequality is motivated as follows. First, between-nation inequality represents, as of today, the greatest source of inequality between individuals (Firebaugh, 2015, Bourguignon and Morrisson, 2002). Besides, future income distribution within a country is subject to policy choices that would be difficult to model.

Many indicators can be used to measure this type of inequality (CharlesColl 2011). The most routinely used index is the Gini index, which computes the dispersion of income, ranging from 0 (perfect equality) to 1 (one individual or entity owns all the income). The Gini index is the ratio of the mean absolute difference between two individuals or entities to twice the mean level of income. If countries indexed by $i$ are ranked based on their per capita income $I_{i}$, with $p_{i}$ their population, we can define the cumulated proportion of income and population as follows: 


$$
\begin{aligned}
p_{c, i} & =\frac{\sum_{k=1}^{i} p_{k}}{\sum_{k=1}^{N} p_{k}} \\
I_{c, i} & =\frac{\sum_{k=1}^{i} I_{k}}{\sum_{k=1}^{N} I_{k}}
\end{aligned}
$$

The Gini index then writes:

$$
\text { Gini }=1-\sum_{k=i}^{N}\left(p_{c, i}-p_{c, i-1}\right)\left(I_{c, i}-I_{c, i-1}\right)
$$

with $I_{c, 0}=0$ and $p_{c, 0}=4$. Appealing for its simplicity, the Gini index is also criticized, notably because it may be regarded as overly sensitive to changes in the middle of the distribution, and because it measures relative inequality (Cowell, 2000). Indeed, a world with more inequality may still be better for the poorest in absolute terms. Thus, we also examine the absolute situation of the bottom $10 \%$, as measured by the first income decile (see section 4.4.

\section{Results}

We compute the Gini index in all scenarios, and analyze the drivers of its evolution over the twenty-first century.

\section{$4.1 \mathrm{~A}$ trend reversal in inequalities}

Both socioeconomic and climate-related uncertainties strongly influence the evolution of future inequalities (figure 1). In many scenarios, inequalities continue to decline for a few years or decades, but as climate change impacts gradually occur, they may outweigh the forecasted economic catch-up by lowincome countries, and inequalities may rise again as a result.

We perform a PRIM analysis to identify the combinations of uncertainties that lead to this trend reversal, using the method described in Guivarch et al. (2016 ${ }^{5}$ The results of this analysis show that there are cases of trend reversal in all socioeconomic pathways, even in the most optimistic ones (see table 3). Inequalities rise again systematically in SSP 4, a socioeconomic world depicting a great divide between rich and poor countries. With the low prospect for catch-up assumed in SSP 3, a trend reversal in inequality can also occur, but only for high damage estimates (namely BHM (0 lag), and all DJO estimates). For other socioeconomic pathways, regressive damage specifications

4 The pairs $\left(p_{c, i}, I_{c, i}\right)$ represent the Lorenz curve: a proportion $p_{c, i}$ of the population earns a proportion $I_{c, i}$ of global income. Graphically, the Gini coefficient is worth half the area between the Lorenz curve and the first bisector.

5 Results from the PRIM analysis are provided in the Appendix. 


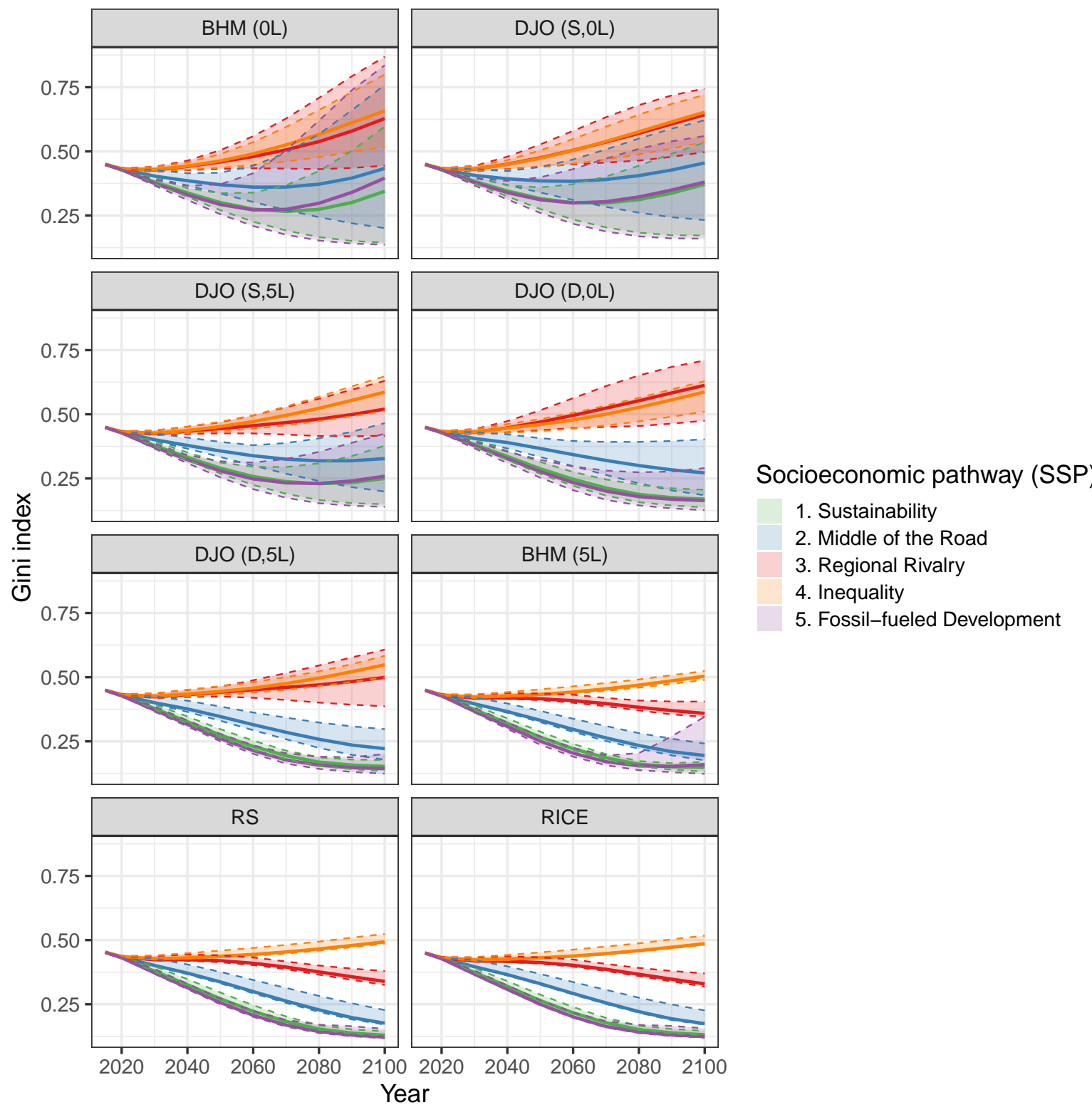

Fig. 1 Evolution of the Gini index over time. A panel corresponds to a damage function. For each socioeconomic pathway, the dotted lines represent the minimum and maximum values of the Gini index, while the plain line is the mean. 'DJO': Dell et al. (2012), 'BHM': Burke et al. (2015), 'RS': Roson and Sartori (2016). For DJO, 'S' and 'D' stand respectively for static and dynamic poor/rich distinction. For DJO and BHM, 'OL' and ' $5 \mathrm{~L}$ ' refer to 0 -year lag or 5-year lag regression. 
Table 3 Each line is a combination where a trend reversal in the Gini occurs, of factors leading to a trend reversal in inequality, as revealed by PRIM analysis. The trend reversal can occur in all SSPs, but in some SSPs only for high damages, a high RCP or a high temperature response.

\begin{tabular}{|c|c|c|c|}
\hline SSP & Damage & $\mathrm{RCP}$ & Temperature response \\
\hline \multirow{3}{*}{ SSP 1} & BHM (0L) & $\geq \operatorname{RCP} 3.4$ & All \\
\hline & DJO $(\mathrm{S}, 5 \mathrm{~L})$ & All & Medium, High \\
\hline & DJO $(\mathrm{S}, 0 \mathrm{~L})$ & $\geq \operatorname{RCP} 3.4$ & All \\
\hline \multirow{3}{*}{ SSP2 } & BHM (0L) & $\geq \operatorname{RCP} 3.4$ & Medium, High \\
\hline & DJO $(\mathrm{S}, 5 \mathrm{~L})$ & $\geq \mathrm{RCP} 3.4$ & Medium, High \\
\hline & DJO (S,0L) & $\geq \mathrm{RCP} 3.4$ & All \\
\hline \multirow{5}{*}{ SSP3 } & BHM (0L) & \multirow{5}{*}{ All } & \multirow{5}{*}{ All } \\
\hline & DJO (S,5L) & & \\
\hline & DJO (S,0L) & & \\
\hline & DJO (D,0L) & & \\
\hline & DJO (D,5L) & & \\
\hline SSP4 & All & All & All \\
\hline \multirow{3}{*}{ SSP5 } & BHM (0L) & $\geq \operatorname{RCP} 3.4$ & \multirow{3}{*}{ All } \\
\hline & DJO (S,5L) & $\geq \operatorname{RCP} 3.4$ & \\
\hline & DJO (S,0L) & $\geq \mathrm{RCP} 3.4$ & \\
\hline
\end{tabular}

(i.e. econometrics-based) slow down the convergence, and make inequalities rise again under strong temperature change (either because of high emission or high temperature response).

In the cases where inequalities rise again, the timing of the trend reversal also varies depending on the uncertainties, in particular the combination of socioeconomic assumptions and damage function (see figure 2). The reversal occurs systematically as early as in the 2020s in SSP 4. In SSP 3, the occurring decade is determined by the damage estimates, but varies between lowest and highest damage estimates. For the more 'optimistic' socioeconomic pathways (SSPs 1, 2 and 5), there is great variability in the date at which the trend reversal occurs for high damage estimates. In such cases, lower emission scenarios or low temperature response scenarios delay the reversal.

\subsection{Analyzing the Gini index using regression trees}

We analyze how the different uncertainties affect the Gini index, and we compute a regression tree to identify the main drivers of its value in 2100 . We use recursive partitioning to select the factors in order to reduce the heterogeneity of the output value ${ }^{6}$ The regression tree identifies socioeconomic assumptions (SSPs) and the damage function as the first two nodes of the decision tree, suggesting that these dimensions are the most influential on inequalities in 2100 (figure 3). The first node splits the scenarios into two groups, the first one composed of scenarios with 'optimistic' socioeconomic assumptions (SSPs 1,2 and 5 ) in terms of convergence between poor and rich countries, and the

6 We used rpart function of R (complexity parameter of rpart function is set at 0.02 , meaning that a split is retained if it increases the fit by a factor 0.02 ) 


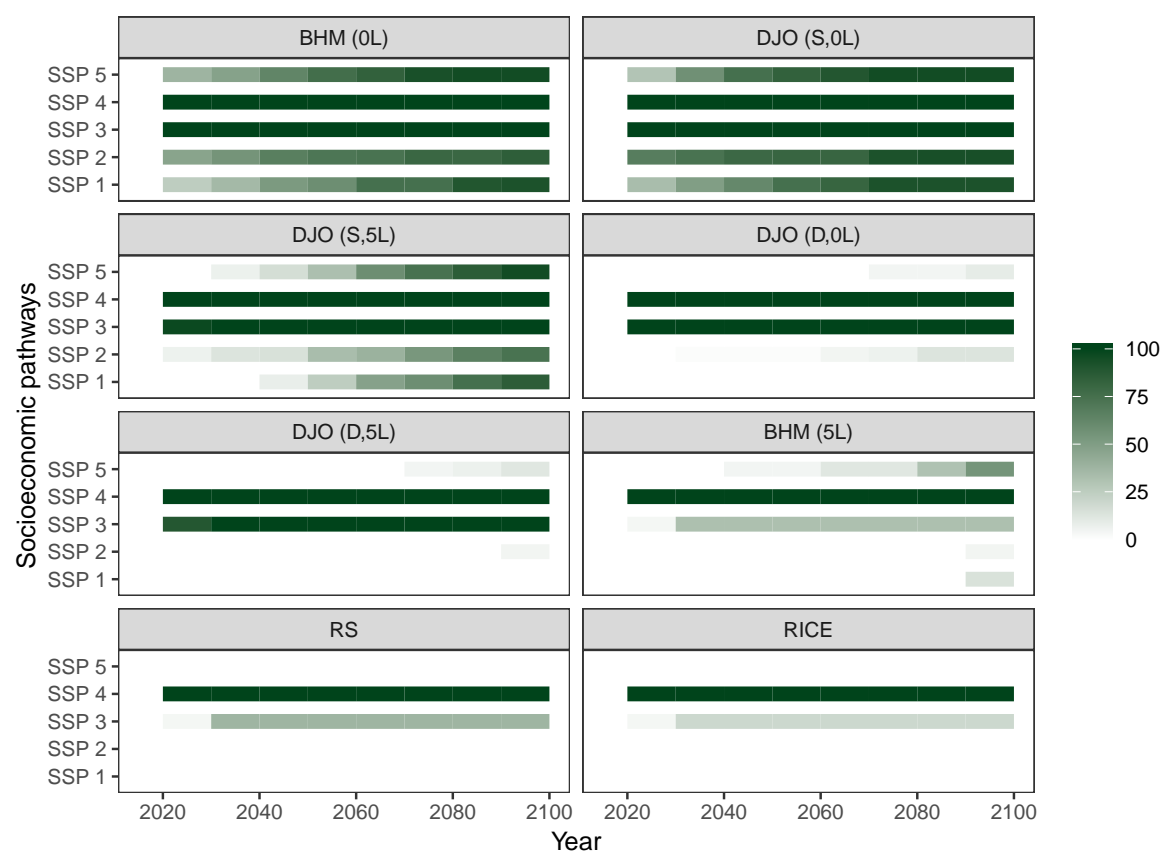

Fig. 2 Cumulated percentage of scenarios where a trend reversal has occurred, for a given combination of damage function and socioeconomic assumptions.

second one composed of scenarios with pessimistic such assumptions (SSPs 3 and 4). Within each branch, the tree further splits scenarios according to the magnitude of climate change damages. Interestingly, the grouping of the damage functions differs across the two branches of the tree. Indeed, when the vulnerability of countries depends on their income (in the 'dynamic' versions of DJO), climate damages strongly depend on the socioeconomic pathway: convergence assumptions limit the effect of climate change on inequalities, because poor countries can shield themselves from climate damages through development. The contrary holds if poor countries are assumed to slowly catch-up with rich countries. Finally, if optimistic SSPs are combined with high damages, the next node splits the remaining scenarios according to the level of emissions. All the other dimensions of uncertainties, that is mitigation costs, their distribution within regions, as well as temperature response uncertainty, contribute to a lesser extent to the Gini index in 2100.

For the highest damage estimates (i.e. mostly econometric estimates), the cascading effect of emission pathway and temperature response uncertainty translate into great variability in the benefits of avoided damages for the poorest, and thus a greater variability of the Gini index in 2100 (figure 4). With the most regressive specifications, damages are such that they may completely cancel out expected convergence in some scenarios, and lead to a higher Gini 


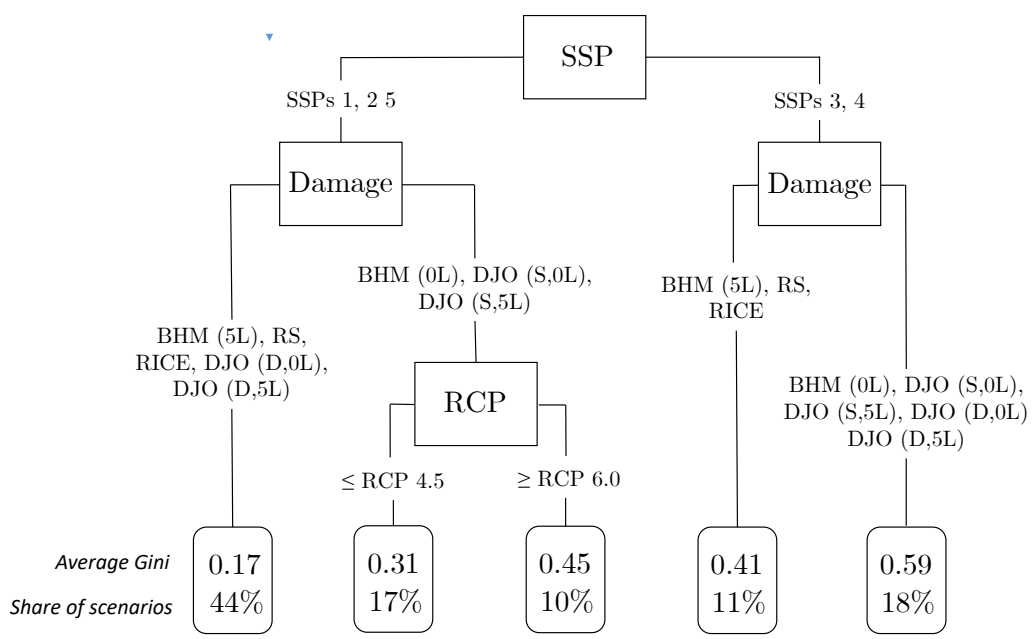

Fig. 3 Regression tree on the value of Gini in 2100. The algorithm splits scenarios to best predict the value of the output, thus generating groups with minimal heterogeneity. In each leaf of the tree, the upper number is the mean of Gini for the scenarios in the box, while the lower number is the percentage of scenarios it represents.

index in 2100 than today. In particular in SSP3, most scenarios with econometric damage estimates show Gini levels higher than today, while it is not the case under low damage functions. Gini index can be higher than today in other socioeconomic pathways, but only when combining the most regressive damage functions (BHM $(0 \mathrm{~L})$ and DJO $(\mathrm{S}, 0 \mathrm{~L})$ ) with the highest emission pathways. However, in the short run (the Gini index in 2050 is shown in figure 5), socioeconomic assumptions appear as the main drivers of inequalities, with limited variability across other dimensions.

\subsection{Does mitigation reduce inequalities?}

We compare inequality levels in 2100 across emissions pathways to analyze how the regressive impacts of climate damages compare to those of mitigation costs. We analyze which emission pathway, all else being equal, has the lowest inequality level (figure 6). Unsurprisingly, lower emission pathways are preferred when assuming regressive damages. We look specifically for the cases in which RCP 2.6 is the preferred emission pathway, because it is the only RCP likely to achieve the $2^{\circ} \mathrm{C}$ target 7 Whether RCP 2.6 performs best in terms of inequality depends primarily on the damage function. With the most regressive damage estimates (BHM, OL), inequalities are always lowest under RCP

\footnotetext{
7 Note that models have not produced this emission pathway under the most pessimistic socioeconomic pathway (SSP 3), where low growth is combined with high challenge to mitigation
} 


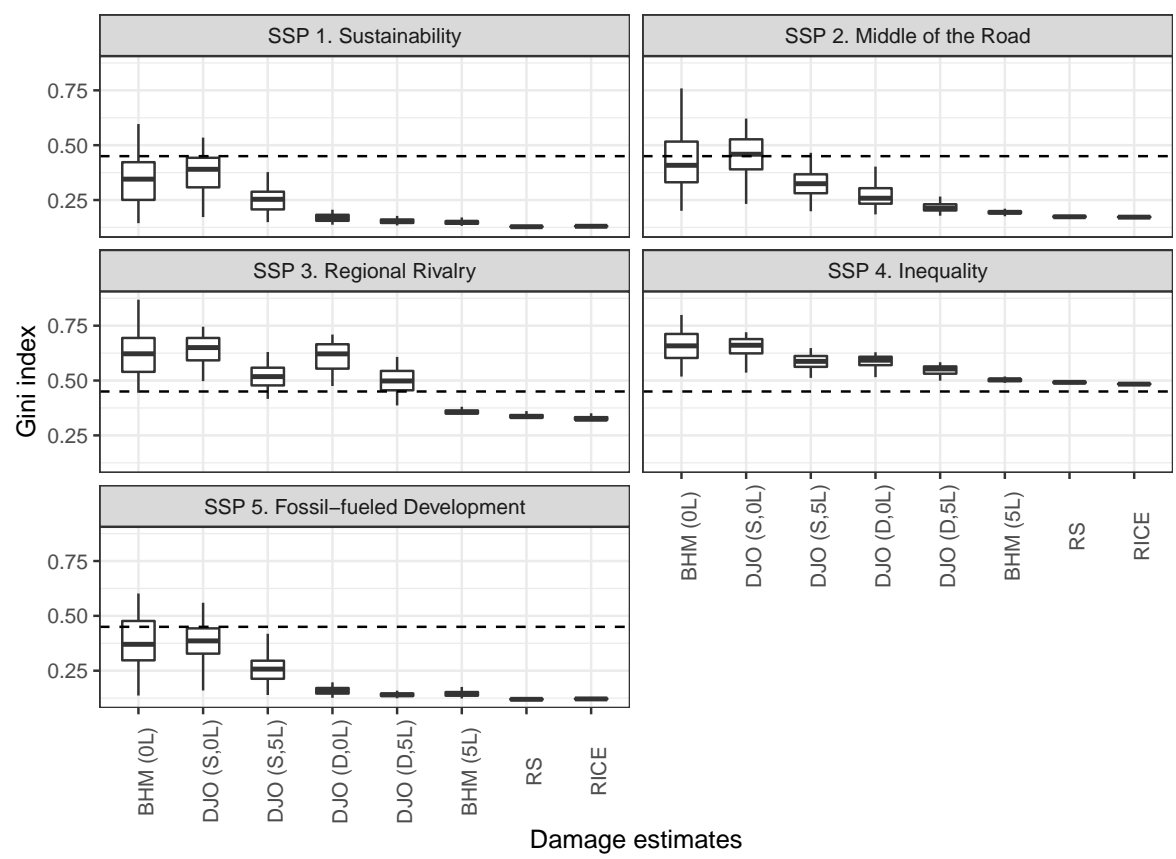

Fig. 4 Boxplot of the Gini index in 2100, for combinations of socioeconomic assumptions (panel) and damage functions (x-axis)

2.6 unless the high baseline emissions of SSP 5 is combined with the highest mitigation costs estimates (WITCH). Under the other econometric damage estimates, RCP 2.6 is the less unequal emission pathway either for optimistic SSPs with low challenges to mitigation $(1,2,4)$, or when mitigation costs are low (all except WITCH). RCP 2.6 is less often the scenario with the lowest inequality levels IAM-based damage functions, i.e. RICE and RS. Netherless, even under low damage estimates, RCP 2.6 may still be the emission pathway with the lowest inequality level in some specific combinations, in particular for optimistic SSPs, provided that mitigation costs are not shared evenly within regions.

Likewise, looking at SSP 3, the damage estimate also primarily drives the comparison across emission pathways, and the same pattern can be observed. For high damages, avoided damages outweigh the cost to keep emissions compatible with RCP 3.4, while the contrary holds in the case of lower damages. Given that SSP 3 depicts a low-growth, low-technical progress world, mitigation is particularly costly, so that the lowest inequality levels do not always coincide with the lowest emission pathway. 


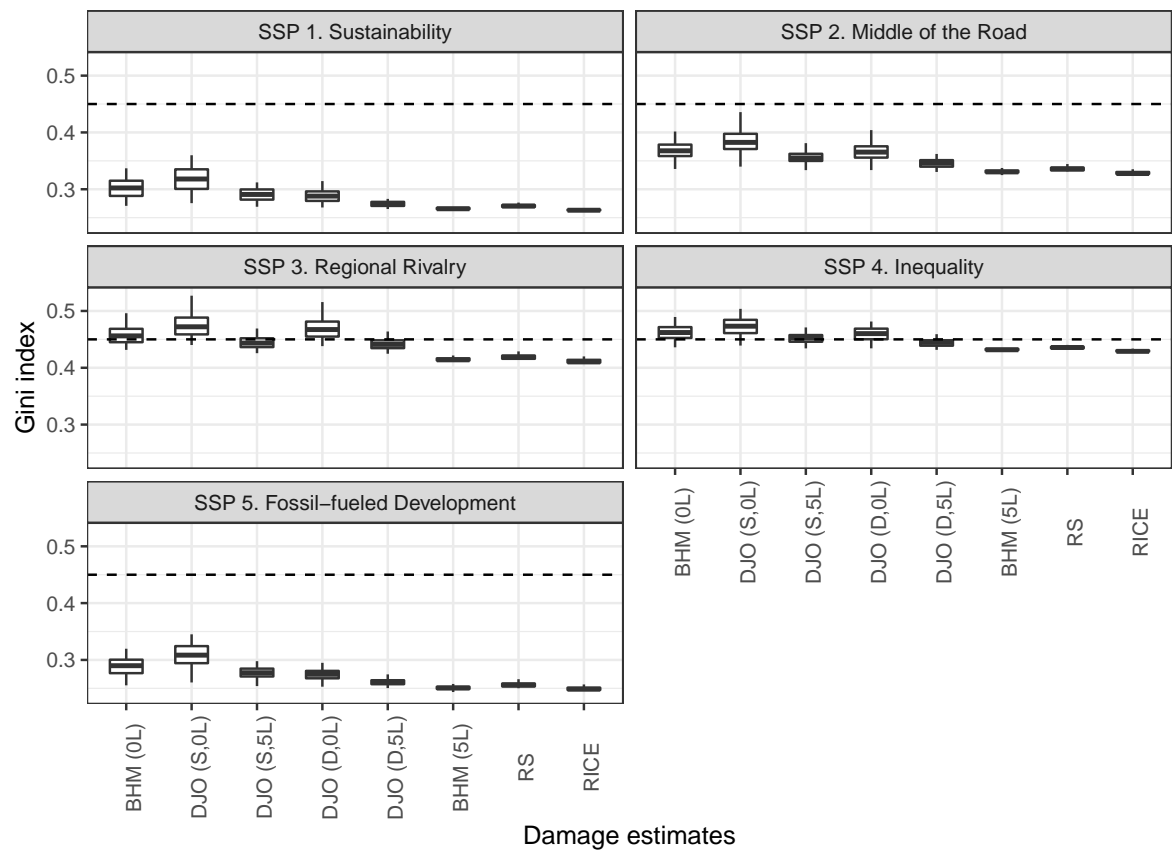

Fig. 5 Boxplot of the Gini index in 2050, for combinations of socioeconomic assumptions (panel) and damage functions (x-axis)

4.4 Does mitigation improve the situation of the poorest?

The Gini index only provides a relative measure of inequality, and thus does not give information about the absolute situation of the poorest. Here, we compute the first income decile in 2100 , which reflects the situation of the poorest $10 \%$ (figure 7). Socioeconomic assumptions appear as the first driver of the situation of the poorest $10 \%$, as it is the case with the Gini index, with differences larger than one order of magnitude across SSPs. There are also strong discrepancies between damage functions, and the most regressive results in terms of Gini are not necessarily the ones for which the situation of the poorest is the worst. However, the first income decile is almost systematically larger under RICE and RS damages than for econometrics-based damage functions.

We also compare the first income decile across emissions pathways (see figure 8). The distribution of the preferred emission pathway based on the value of the first income decile is generally close to that based on the Gini index. As it was the case for inequality, the situation of the poorest $10 \%$ tends to be better in lower emission pathways for econometrics-based damage functions. However, for the dynamic specification of DJO (0-lag) in high-growth SSP 5, rapid convergence allows the poorest $10 \%$ to become less vulnerable to climate change, so that mitigation does not improve their situation. Even under RICE 


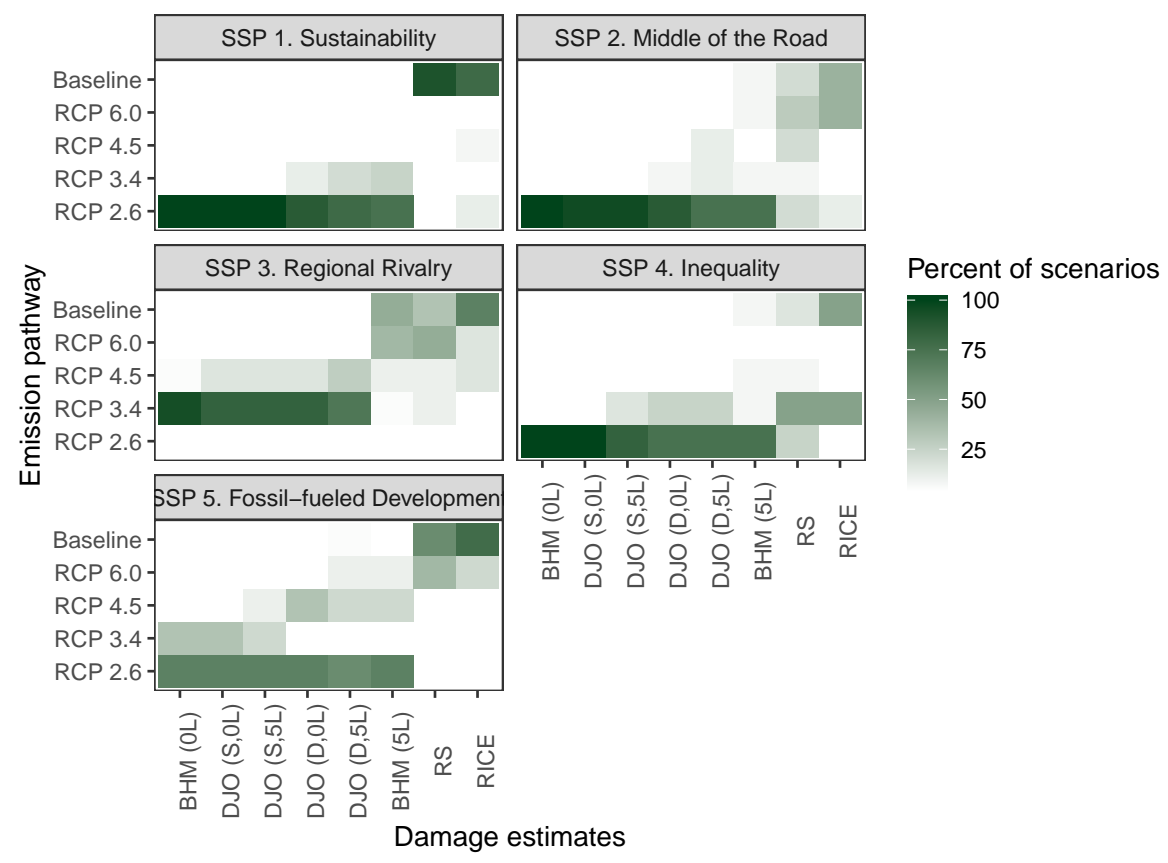

Fig. 6 Which emission pathway has the lowest inequality level? We compare inequality levels across emission pathways, all else being equal. The graph shows the percentage of scenarios in which each emission pathway has the lowest inequality level. We group scenarios based on SSP (panel) and damage estimates (x-axis). For instance, in SSP 1 and under BHM (0L) damages, RCP 2.6 always has the lowest Gini.

damages, the first income decile can be higher for higher emission pathways. It is the case for SSPs where a significant number of countries stay behind (SSPs 3 and 4); and in SSPs 2 and 5, although only under low or moderate temperature response. Finally, with RS damages function, the poorest $10 \%$ are better off without mitigation if we assume low growth (SSP 3) or high mitigation costs (WITCH).

\section{Discussion}

\subsection{Limitations of the study}

Our results are conditional on the relative magnitude of the mitigation and damage cost estimates we use, as well as on their distribution across countries. We highlight that many outcomes regarding future inequality will depend on the level of damages. Although we have tried to include as many estimates as possible in the analysis, IAM-based and econometrics damages all have limitations (Diaz and Moore, 2017). Econometrics-based damage functions 


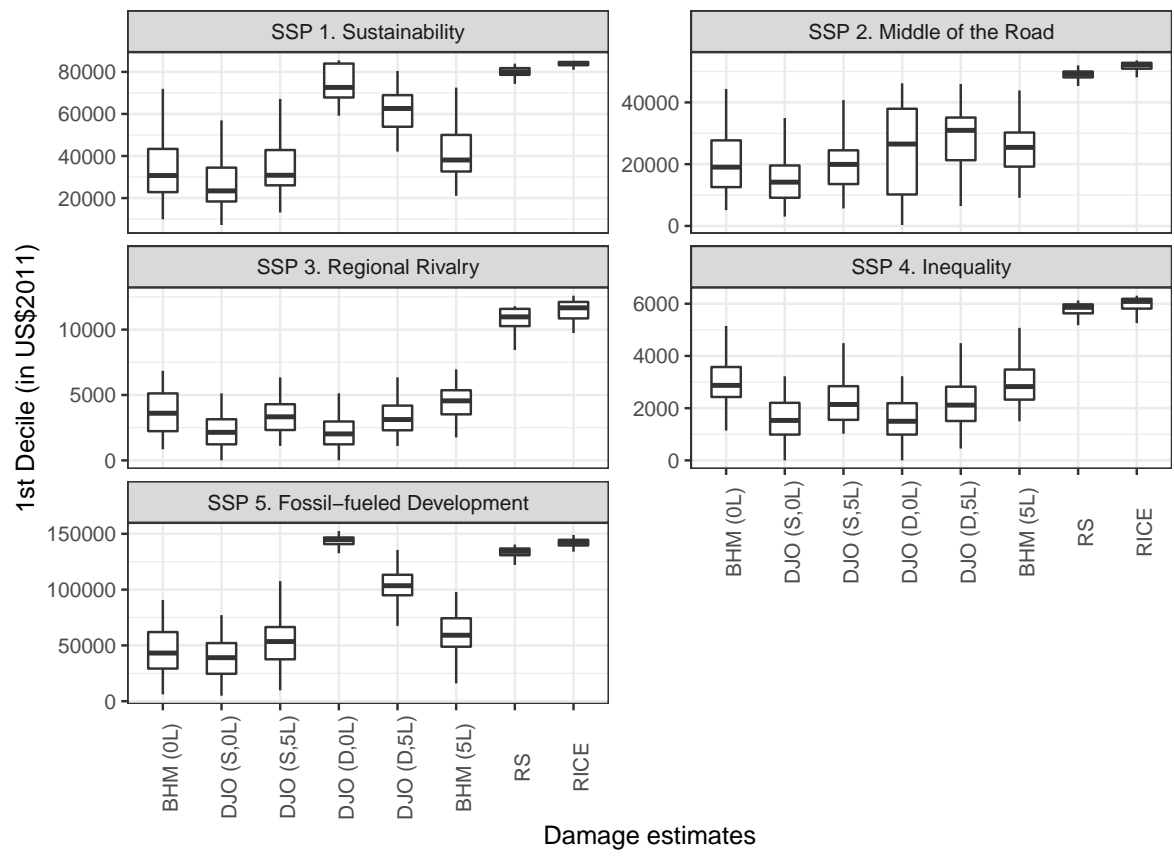

Fig. 7 Boxplot of the 1st income decile in 2100, for combinations of socioeconomic assumptions (panel) and damage functions (x-axis). Note that the scale of the y-axis differs across panels.

represent a large share of the estimates used here. Although they allow for an empirically-grounded country-by-country treatment of damages, the validity of extrapolating into the future the short-term effects of weather on economic growth to assess the economic impact of climate change is subject to debate (Schlenker and Auffhammer, 2018). On the one hand, long-term adaptation may occur and reduce negative impacts. On the other hand, impacts could be exacerbated by non-linear effects outside of historical experience and by other potential sources of economic loss associated with climate change but not linked to temperature change, such as sea-level rise. Which of these two effects will prevail remains uncertain.

Another, related, limitation is the difficulty to account for the vulnerability of countries, as well as their ability to adapt to climate change in different socioeconomic pathways. Depending on the socioeconomic pathway, it may be more or less challenging - and thus costly - to adapt to a given temperature change. We account for some form of adaptation in the dynamic version of DJO damages, where damages depend on the level of income of the country. However, we do not proceed likewise for the other damage cases. Exploring in a more sophisticated manner the ability of future societies to cope with temperature changes would greatly improve the study, and strengthen the 


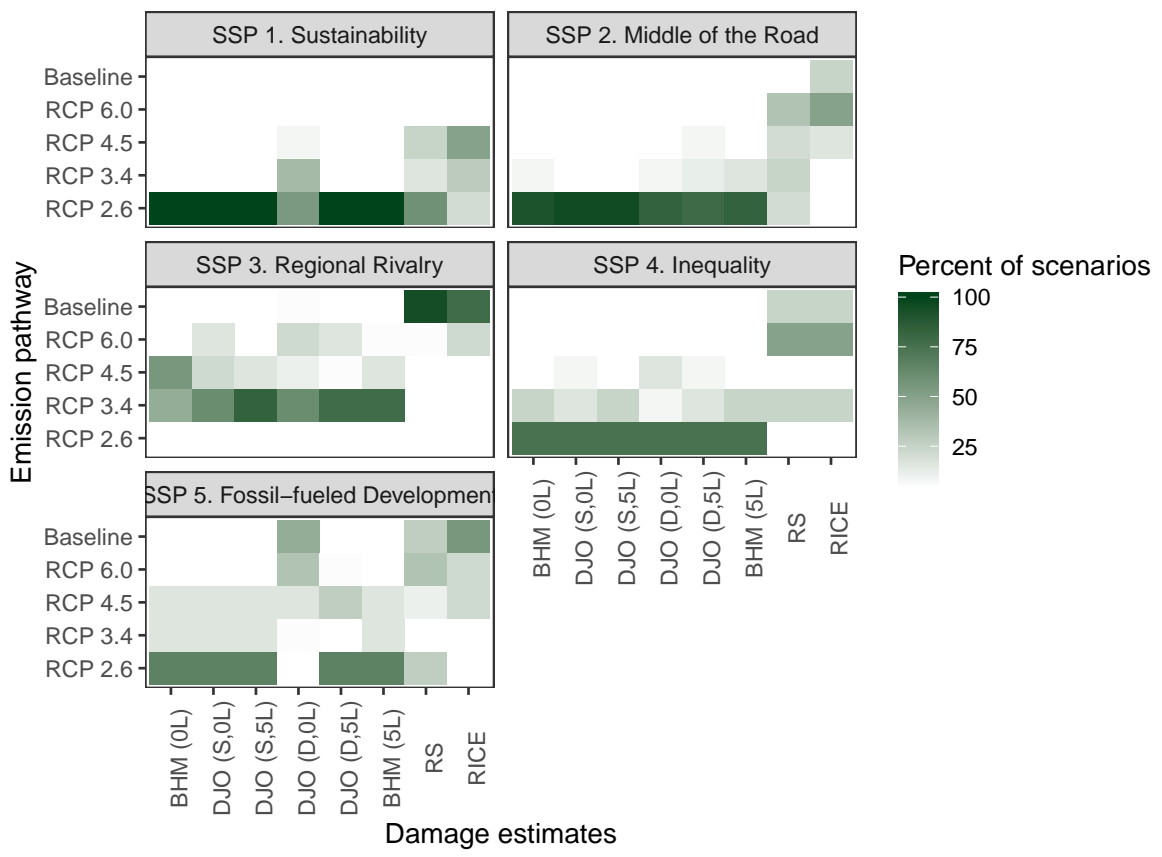

Fig. 8 What is the most favorable emission pathway in terms of the situation of the poorest $10 \%$ ? We compare first income decile levels across emission pathways, all else being equal. The graph shows the percentage of scenarios in which each emission pathway has the greater first income decile. We group scenarios based on SSP (panel) and damage estimates (x-axis). For instance, in SSP 1 and with BHM (0L) damages, RCP 2.6 is always the emission pathway in which the situation of the poorest $10 \%$ is the best.

role of the socioeconomic pathway, as it does in the dynamic setting of DJO damages, but it would also increase its complexity.

The magnitude of the actual macroeconomic mitigation costs may also exceed the evaluations given by IAMs that quantified the SSPs, in particular considering real-world frictions and second-best mechanisms which were not accounted for by those models (Guivarch et al. 2011). In addition, the distribution of mitigation costs among countries will ultimately result from the relative ambition for emissions reduction as defined by their nationally determined contribution to the Paris Agreement, the stringency of policies implemented to reach those, and international climate finance and technology transfer mechanisms (Aldy et al., 2016). The distribution of costs may therefore be more or less regressive than the distribution implied by the mitigation policies represented by the IAMs in the SSP database. Many effort-sharing approaches, for instance accounting for historical responsibility, lead to more stringent targets for developed countries, suggesting that international negotiations may lead to distributions that are less regressive than cost-optimal approaches (van den Berg et al. 2019). Considering such cases would reduce 
the burden of mitigation on poor countries, and thus reinforce the result that mitigation can reduce inequalities.

Considering inequalities among individuals (Dennig et al., 2015; Alvaredo et al. 2018) and not only between countries, and accounting for dimensions of inequality beyond income, such as health inequalities, would complement our analysis of the inequality implications of climate change damages and mitigation. Such extensions would bring further complexity, but have the potential to amplify the results because poor households are particularly vulnerable to climate change impacts (Hallegatte and Rozenberg, 2017). Health inequalities would probably worsen under severe climate change, since health impacts due to climate change disproportionally affect the poor (Patz et al., 2005, Haines et al. 2006), and mitigation generally results in health co-benefits (Smith et al. 2014).

\subsection{Conclusion}

We study how greenhouse gas reduction may affect inequality through mitigation costs and avoided climate damages, with effects going in opposing directions. We build scenarios to account for their influence on future inequalities, and explore uncertainties along different dimensions: socioeconomic assumptions, emission pathways, mitigation costs, the regressivity of mitigation costs, temperature response, and climate change damages. We show that socioeconomic assumptions and climate change damages are the main drivers of the outcomes in the long term. The emission pathway also influences future inequalities, while the temperature response, the mitigation costs and their distribution play a lesser role. In most scenarios, inequalities among countries decline in the short to medium run, but can start rising again as climate change impacts gradually outweigh the expected economic convergence between lowand high-income countries. We show this occurs systematically in scenarios assuming low socioeconomic convergence between rich and poor countries (SSP 4). It can occur in all other socioeconomic pathways when considering high (i.e. econometrics-based) damage, but only under the most pessimistic temperature responses or the highest emission pathways. Whether mitigation reduces inequalities depends primarily on damage estimates. Under the highest damage estimates, it is very likely that inequalities may rise again, in particular in socioeconomic pathways with rather low challenge to mitigation, and when mitigation costs estimates are low. Mitigation can also reduce inequalities under less regressive damage functions, though under more specific assumptions regarding socioeconomic evolution and mitigation costs. In such scenarios, the benefits of avoided damages dominate the regressive effect of climate policies. The same drivers play a crucial role when looking at the situation of the poorest $10 \%$, and the benefits of avoided damages on the first income decile outweigh those of mitigation costs in the same scenarios.

Our results are subject to several caveats and should be interpreted with caution. Nonetheless, they indicate that the cascading uncertainties in emis- 
sion pathways, temperature and damage estimates can lead the distributional impacts of future climate change to counterbalance the projected convergence of countries' incomes. We further stress the divide between IAM- and econometrics-based damage functions, showing that they do not only differ in terms of the aggregate level of damage, but also in terms of their effect on inequality. If climate change is as regressive as econometrics-based damage functions suggest, climate mitigation policies are key to limit the rise of future inequalities between countries.

Acknowledgements The authors would like to thank three anonymous reviewers for their very valuable feedbacks. The authors would also like to thank Stéphane Hallegatte, Eloi Laurent, Louis-Gaëtan Giraudet and participants to the 2018 EAERE-VIU-FEEM Summer School on Climate Change Assessment in Venice. The authors acknowledge funding provided by the NAVIGATE project (H2020/20192023, grant agreement number 821124) of the European Commission. 
References

Aldy J, Pizer W, Tavoni M, Reis LA, Akimoto K, Blanford G, Carraro C, Clarke LE, Edmonds J, Iyer GC (2016) Economic tools to promote transparency and comparability in the Paris Agreement. Nature Climate Change 6(11):1000

Aldy JE, Pizer WA, Akimoto K (2017) Comparing emissions mitigation efforts across countries. Climate Policy 17(4):501-515, DOI 10.1080/14693062. 2015.1119098, URL https://doi.org/10.1080/14693062.2015.1119098

Alvaredo F, Chancel L, Piketty T, Saez E, Zucman G (2018) World Inequality Report 2018. Tech. rep., URL http://wir2018.wid.world/

Barro RJ, Sala-i Martin X (2004) Economic Growth: MIT Press. Cambridge, Massachusettes

van den Berg NJ, van Soest HL, Hof AF, den Elzen MGJ, van Vuuren DP, Chen W, Drouet L, Emmerling J, Fujimori S, Hhne N, Kberle AC, McCollum D, Schaeffer R, Shekhar S, Vishwanathan SS, Vrontisi Z, Blok K (2019) Implications of various effort-sharing approaches for national carbon budgets and emission pathways. Climatic Change DOI 10.1007/s10584-019-02368-y, URL https : //doi .org/10.1007/s10584-019-02368-y

Bourguignon F, Morrisson C (2002) Inequality among world citizens: 18201992. American economic review 92(4):727-744

Burke M, Hsiang SM, Miguel E (2015) Global non-linear effect of temperature on economic production. Nature 527(7577):235-239

Charles-Coll JA (2011) Understanding income inequality: concept, causes and measurement. International Journal of Economics and Management Sciences $1(3): 17-28$

Cowell FA (2000) Measurement of inequality. Handbook of income distribution $1: 87-166$

Dell M, Jones BF, Olken BA (2012) Temperature shocks and economic growth: Evidence from the last half century. American Economic Journal: Macroeconomics pp 66-95

Dellink R, Chateau J, Lanzi E, Magn B (2017) Long-term economic growth projections in the Shared Socioeconomic Pathways. Global Environmental Change 42:200-214, DOI 10.1016/j.gloenvcha.2015.06.004, URL http: //www.sciencedirect.com/science/article/pii/S0959378015000837

Dennig F, Budolfson MB, Fleurbaey M, Siebert A, Socolow RH (2015) Inequality, climate impacts on the future poor, and carbon prices. Proceedings of the National Academy of Sciences 112(52):15827-15832, DOI 10.1073/pnas. 1513967112, URL http://www .pnas .org/content/112/52/15827

Diaz D, Moore F (2017) Quantifying the economic risks of climate change. Nature Climate Change 7(11):774

Edenhofer O, Pichs-Madruga R, Sokona Y, Kadner S, Minx JC, Brunner S, Agrawala S, Baiocchi G, Bashmakov IA, Blanco G, Broome J, Bruckner T, Bustamante M, Clarke L, Conte Grand M, Creutzig F, Cruz-Nez X, Dhakal S, Dubash NK, Eickemeier P, Farahani E, Fischedick M, Fleurbaey M, Fulton L, Gerlagh R, Gmez-Echeverri L, Gupta S, Harnisch J, Jiang K, 
Jotzo F, Kartha S, Klasen S, Kolstad C, Krey V, Kunreuther H, Lucon O, Masera O, Mulugetta Y, Norgaard RB, Patt A, Ravindranath NH, Riahi K, Roy J, Sagar AD, Schaeffer R, Schlmer S, Seto KCY, Seyboth K, Sims R, Smith P, Somanathan E, Stavins R, von Stechow C, Sterner T, Sugiyama T, Suh S, rge Vorsatz D, Urama K, Venables A, Victor DG, Weber E, Zhou D, Zou J, Zwickel T (2014) Technical Summary. In: Climate Change 2014: Mitigation of Climate Change. Contribution of Working Group III to the Fifth Assessment Report of the Intergovernmental Panel on Climate Change [Edenhofer, O., R. Pichs-Madruga, Y. Sokona, E. Farahani, S. Kadner, K. Seyboth, A. Adler, I. Baum, S. Brunner, P. Eickemeier, B. Kriemann, J. Savolainen, S. Schlmer, C. von Stechow, T. Zwickel and J.C. Minx (eds.)]. Cambridge University Press, Cambridge, United Kingdom and New York, NY, USA.

Firebaugh G (2015) Global Income Inequality. In: Emerging Trends in the Social and Behavioral Sciences, John Wiley \& Sons, Inc., DOI 10.1002/ 9781118900772.etrds0149, URL http://onlinelibrary.wiley.com/doi/ 10.1002/9781118900772. etrds0149/abstract

Fujimori S, Kubota I, Dai H, Takahashi K, Hasegawa T, Liu JY, Hijioka Y, Masui T, Takimi M (2016) Will international emissions trading help achieve the objectives of the Paris Agreement? Environmental Research Letters 11(10):104001

Fujimori S, Hasegawa T, Krey V, Riahi K, Bertram C, Bodirsky BL, Bosetti V, Callen J, Desprs J, Doelman J (2019) A multi-model assessment of food security implications of climate change mitigation. Nature Sustainability $2(5): 386$

Georgeson L, Maslin M, Poessinouw M, Howard S (2016) Adaptation responses to climate change differ between global megacities. Nature Climate Change 6(6):584-588, DOI 10.1038/nclimate2944, URL https://www.nature.com/ articles/nclimate2944

Guivarch C, Crassous R, Sassi O, Hallegatte S (2011) The costs of climate policies in a second-best world with labour market imperfections. Climate Policy 11(1):768-788

Guivarch C, Rozenberg J, Schweizer V (2016) The diversity of socio-economic pathways and $\mathrm{CO} 2$ emissions scenarios: Insights from the investigation of a scenarios database. Environmental modelling \& software 80:336-353

Haines A, Kovats RS, Campbell-Lendrum D, Corvalan C (2006) Climate change and human health: Impacts, vulnerability and public health. Public Health 120(7):585-596, DOI 10.1016/j.puhe.2006.01.002, URL http: //www.sciencedirect.com/science/article/pii/S0033350606000059

Hallegatte S, Rozenberg J (2017) Climate change through a poverty lens. Nature Climate Change 7(4):250-256

Hasegawa T, Fujimori S, Havlk P, Valin H, Bodirsky BL, Doelman JC, Fellmann T, Kyle P, Koopman JF, Lotze-Campen H (2018) Risk of increased food insecurity under stringent global climate change mitigation policy. Nature Climate Change 8(8):699 
Hawksworth J, Tiwari A (2011) The World in 2050: The accelerating shift of global economic power: challenges and opportunities. PWC

Hellebrandt T, Mauro P (2015) The future of worldwide income distribution Krey V (2014) Global energyclimate scenarios and models: a review. Wiley Interdisciplinary Reviews: Energy and Environment 3(4):363-383

Leimbach M, Bauer N, Baumstark L, Edenhofer O (2010) Mitigation Costs in a Globalized World: Climate Policy Analysis with REMIND-R. Environmental Modeling \& Assessment 15(3):155-173, DOI 10.1007/s10666-009-9204-8, URL https://doi.org/10.1007/s10666-009-9204-8

Liu JY, Fujimori S, Masui T (2016) Temporal and spatial distribution of global mitigation cost: INDCs and equity. Environmental Research Letters 11(11):114004

Mendelsohn R, Dinar A, Williams L (2006) The distributional impact of climate change on rich and poor countries. Environment and Development Economics 11(2):159-178

Milanovic B (2006) Economic integration and income convergence: not such a strong link? The Review of Economics and Statistics 88(4):659-670

Milanovic B (2011) Worlds apart: Measuring international and global inequality. Princeton University Press

Milanovic B (2016) Global Inequality: A New Approach for the Age of Globalization. Harvard University Press, google-Books-ID: 0Sa7CwAAQBAJ

Nordhaus W (2008) A question of balance. Yale University Press New Haven

Nordhaus W (2014) Estimates of the Social Cost of Carbon: Concepts and Results from the DICE-2013r Model and Alternative Approaches. Journal of the Association of Environmental and Resource Economists 1(1/2):273312, DOI 10.1086/676035, URL https://www.journals.uchicago.edu/ doi/abs/10.1086/676035

Nordhaus W, Yang Z (1996) A Regional Dynamic General-Equilibrium Model of Alternative Climate-Change Strategies. American Economic Review 86:741-65

OECD (2018) Domestic product - GDP long-term forecast - OECD Data. URL http://data.oecd.org/gdp/gdp-long-term-forecast.htm

Oppenheimer M, Campos M, Warren R, Birkmann J, Luber G, Oneill B, Takahashi K (2014) Emergent risks and key vulnerabilities. Climate Change 2014: Impacts, Adaptation, and Vulnerability Working Group II Contribution to the IPCC 5th Assessment Report pp 1-107

Patz JA, Campbell-Lendrum D, Holloway T, Foley JA (2005) Impact of regional climate change on human health. Nature 438(7066):310-317, DOI 10.1038/nature04188, URL https://www.nature.com/articles/ nature04188

Riahi K, Van Vuuren DP, Kriegler E, Edmonds J, Oneill BC, Fujimori S, Bauer N, Calvin K, Dellink R, Fricko O (2017) The shared socioeconomic pathways and their energy, land use, and greenhouse gas emissions implications: an overview. Global Environmental Change 42:153-168

Rodrik D (2011) The Future of Economic Convergence. Tech. Rep. 17400, National Bureau of Economic Research, Inc, URL https://ideas.repec. 
org/p/nbr/nberwo/17400.html

Roson R, Sartori M (2016) Estimation of Climate Change Damage Functions for 140 Regions in the GTAP 9 Data Base. Journal of Global Economic Analysis 1(2):78-115, DOI 10.21642/JGEA.010202AF, URL https : //www . jgea.org/resources/jgea/ojs/index.php/jgea/article/view/31

Schlenker W, Auffhammer M (2018) The cost of a warming climate. Nature 557(7706):498, DOI 10.1038/d41586-018-05198-7, URL http://www . nature.com/articles/d41586-018-05198-7

Smith KR, Woodward A, Campbell-Lendrum D, Chadee DD, Honda Y, Liu Q, Olwoch JM, Revich B, Sauerborn R (2014) Human health: impacts, adaptation, and co-benefits. Climate change 2014

Spence M (2011) The next convergence: The future of economic growth in a multispeed world. Farrar, Straus and Giroux

Stern N (2007) The economics of climate change: the Stern review. cambridge University press

Stocker TF, Qin D, Plattner GK, Tignor M, Allen SK, Boschung J, Nauels A, Xia Y, Bex B, Midgley BM (2013) IPCC, 2013: climate change 2013: the physical science basis. Contribution of working group I to the fifth assessment report of the intergovernmental panel on climate change

Tol RS, Downing TE, Kuik OJ, Smith JB (2004) Distributional aspects of climate change impacts. Global Environmental Change 14(3):259-272

Tol RSJ (2018) The Economic Impacts of Climate Change. Review of Environmental Economics and Policy 12(1):4-25, DOI 10.1093/reep/rex027, URL https://academic.oup.com/reep/article/12/1/4/4804315

Waisman H, Guivarch C, Grazi F, Hourcade JC (2012) The IMACLIM-R model: infrastructures, technical inertia and the costs of low carbon futures under imperfect foresight. Climatic Change 114(1):101-120 